\title{
Development of Digital Control for High Power Permanent-Magnet Synchronous Motor Drives
}

\author{
Ming-Hung Chen and Hao-Ting Tseng \\ Department of Electrical Engineering, Ming Chi University of Technology, 84 Gungjuan Road, Taishan District, \\ New Taipei City 24301, Taiwan
}

Correspondence should be addressed to Ming-Hung Chen; mhchen@mail.mcut.edu.tw

Received 13 April 2014; Accepted 10 May 2014; Published 2 June 2014

Academic Editor: Her-Terng Yau

Copyright (C) 2014 M.-H. Chen and H.-T. Tseng. This is an open access article distributed under the Creative Commons Attribution License, which permits unrestricted use, distribution, and reproduction in any medium, provided the original work is properly cited.

This paper is concerned with the development of digital control system for high power permanent-magnet synchronous motor (PMSM) to yield good speed regulation, low current harmonic, and stable output speed. The design of controller is conducted by digitizing the mathematical model of PMSM using impulse invariance technique. The predicted current estimator, which is insensitive to motor feedback currents, is proposed to function under stationary frame for harmonic current suppression. In the $\mathrm{AC} / \mathrm{DC}$ power converter, mathematical model and $d c$-link voltage limit of the three-phase switch-mode rectifier are derived. In addition, a current controller under synchronous frame is introduced to reduce the current harmonics and increase the power factor on the input side. A digital control system for $75 \mathrm{~kW}$ PMSM is realized with digital signal processor (R5F5630EDDFP). Experimental results indicate that the total harmonic distortion of current is reduced from $4.1 \%$ to $2.8 \%$ for $50 \mathrm{~kW}$ output power by the proposed predicted current estimator technique.

\section{Introduction}

Basically, the structure of PMSM, which consists of threephase windings on stator but permanent magnets on rotor, is similar to traditional synchronous motor. Because there are no excitation circuit, slip rings, and brushes, the PMSM features advantages of simple structure and high efficiency. In the vector-controlled PMSM drives, the output of speed controller provides the reference value for current controllers; therefore, it is suitable for proportional-integral (PI) controller in precision servo drive applications [1]. One of popular approaches to drive PMSM uses direct torque control (DTC) because of the merits of simple structure, quick dynamic response, and strong robustness against rotor parameters. However, it also presents some disadvantages of large torque/flux ripples [2]. The DTC uses hysteresis comparators which only consider the signs of torque and flux errors so their amplitudes are not differentiated [3]. In this paper, the high power PMSM $(75 \mathrm{~kW})$ is characterized by low equivalent resistance and inductance. Thus it is difficult to implement the motor drive. Currently, the PMSM drive system is mostly implemented by inverters with high switching frequency. Because of the low equivalent resistance and inductance characteristic, currents feedback delay, and resolution limitation of digital controller, it introduces lots of current harmonics to motor so that it affects the performance of the electromagnetic torque output of the motor. Torque ripple is a critical concern in many high power PMSMs, and the existence of torque ripple degrades the control stability [4]. In order to alleviate these drawbacks and reduce current harmonics in steady state, the motor mathematical model is used to estimate the motor currents and thus to compensate for current harmonics caused by high switching frequency and to improve problems of current feedback delay and resolution limitation of digital control [5]. The predicted current estimator used in this paper obtains motor current feedback and accelerates the convergence with closed-loop control. It can not only reduce the steady-state current harmonics, but also accelerate the speed and current transient response. Comparing with other papers, the proposed system features the advantages of high power level, low current harmonic, and fast response. In summary, the control strategy 
and pulse-width modulation (PWM) will be implemented by a low cost digital signal processor (DSP). The analysis of predicted current estimator will be discussed in detail.

\section{System Configuration}

The configuration of the proposed system shown in Figure 1 consists of two parts: power converter and digital signal control module. As indicated above, the power converter includes an AC/DC power converter, a high power inverter, gate drive, and current sensors. The proposed system can thus transfer energy from electrical to mechanical forms with good power quality. As to the digital signal control module, it includes a DSP to realize the controller of the proposed system. A 12-bit analog-to-digital converter (ADC) and a PWM module are built in the DSP to reduce the hardware complexity and improve the reliability as well as maintainability of the system.

\section{Operation Principles}

In order to reduce current harmonics to high power PMSM, a predicted current estimator for closed-loop control is proposed. By current sensors at the output of inverter, one can obtain three-phase currents and then transform them into stationary frame. The $q$ - and $d$-axis currents in stationary frame thus yield the peak value of output current. The currents to PMSM can then be calculated by predicted current estimator. On the other hand, a speed regulator adjusts the $q$-axis current from rotational encoder which is used to calculate rotor speed. Thus the motor speed can remain constant all the time. The detailed analysis is discussed in the following part.

3.1. Mathematical Model of PMSM. The equivalent circuit of PMSM is shown in Figure 2. The voltage equation can be written as [6]

$$
v_{a b c s}=\widetilde{r}_{s} i_{a b c s}+\frac{d}{d t} \lambda_{a b c s}
$$

where

$$
\begin{aligned}
v_{a b c s} & =\left[\begin{array}{lll}
v_{a s} & v_{b s} & v_{c s}
\end{array}\right]^{T}, \\
i_{a b c s} & =\left[\begin{array}{lll}
i_{a s} & i_{b s} & i_{c s}
\end{array}\right]^{T}, \\
\lambda_{a b c s} & =\left[\begin{array}{lll}
\lambda_{a s} & \lambda_{b s} & \lambda_{c s}
\end{array}\right]^{T}, \\
\widetilde{r}_{s} & =\left[\begin{array}{lll}
r_{s} & 0 & 0 \\
0 & r_{s} & 0 \\
0 & 0 & r_{s}
\end{array}\right] .
\end{aligned}
$$

$v_{a b c s}$ and $i_{a b c s}$ denote the phase voltages and line currents of motor, respectively; $r_{s}$ and $\lambda_{a b c s}$ are the equivalent resistance and flux linkages of stator. Assume that the flux harmonics of rotor and stator are negligible. Under this circumstance, the fluxes of rotor and stator are sinusoidally distributed. Therefore, one has the flux linkage

$$
\lambda_{a b c s}=\widetilde{L_{s}} i_{a b c s}+\widetilde{\lambda}_{m}^{\prime},
$$

where

$$
\begin{gathered}
\widetilde{L}_{s}=\left[\begin{array}{ccc}
L_{\ell s}+L_{m s} & -\frac{1}{2} L_{m s} & -\frac{1}{2} L_{m s} \\
-\frac{1}{2} L_{m s} & L_{\ell_{s}}+L_{m s} & -\frac{1}{2} L_{m s} \\
-\frac{1}{2} L_{m s} & -\frac{1}{2} L_{m s} & L_{\ell s}+L_{m s}
\end{array}\right], \\
\tilde{\lambda}_{m}^{\prime}=\lambda_{m}^{\prime}\left[\begin{array}{c}
\sin \theta_{r} \\
\sin \left(\theta_{r}-120^{\circ}\right) \\
\sin \left(\theta_{r}+120^{\circ}\right)
\end{array}\right],
\end{gathered}
$$

where $\theta_{r}=\int \omega_{r} d t ; L_{m s}=N_{s}^{2} / \Re_{m} ; \theta_{r}$ and $\omega_{r}$ are rotor flux angle and speed, respectively; $N_{s}$ and $L_{l s}$ are equivalent turns and leakage inductance of stator winding, respectively; $\mathfrak{R}_{m}$ is equivalent reluctance of stator; $\lambda_{m}^{\prime}$ is the equivalent flux linkage of rotor referred to stator.

From (1) (4), one can obtain the following phase voltage of motor:

$$
v_{a b c s}=r_{s} i_{a b c s}+L_{s} \frac{d}{d t} i_{a b c s}+e_{a b c s},
$$

where $e_{a b c s}$ denotes the internal voltage of motor and is proportional to $\omega_{r}$. That is,

$$
e_{a b c s}=\omega_{r} \lambda_{m}^{\prime}\left[\begin{array}{c}
\cos \theta_{r} \\
\cos \left(\theta_{r}-120^{\circ}\right) \\
\cos \left(\theta_{r}+120^{\circ}\right)
\end{array}\right] \text {. }
$$

For modelling and control design, three-phase variables in stationary frame can be transformed into two-axis stationary frame. This yields [7]

$$
\begin{aligned}
& {\left[\begin{array}{l}
f_{q s}^{s} \\
f_{d s}^{s} \\
f_{0 s}^{s}
\end{array}\right]=\frac{2}{3}\left[\begin{array}{ccc}
1 & -\frac{1}{2} & -\frac{1}{2} \\
0 & -\frac{\sqrt{3}}{2} & \frac{\sqrt{3}}{2} \\
\frac{1}{2} & \frac{1}{2} & \frac{1}{2}
\end{array}\right]\left[\begin{array}{l}
f_{a s} \\
f_{b s} \\
f_{c s}
\end{array}\right],} \\
& {\left[\begin{array}{l}
f_{a s} \\
f_{b s} \\
f_{c s}
\end{array}\right]=\left[\begin{array}{ccc}
1 & 0 & 1 \\
-\frac{1}{2} & -\frac{\sqrt{3}}{2} & 1 \\
-\frac{1}{2} & \frac{\sqrt{3}}{2} & 1
\end{array}\right]\left[\begin{array}{l}
f_{q s}^{s} \\
f_{d s}^{s} \\
f_{0 s}^{s}
\end{array}\right],}
\end{aligned}
$$

where subscripts $q$ and $d$ are used to denote the components of $q$ - and $d$-axis in two-axis frame, respectively. The two-axis variables in stationary frame can be transferred to rotating frame as follows [7]:

$$
\begin{aligned}
& {\left[\begin{array}{l}
f_{q s}^{r} \\
f_{d s}^{r}
\end{array}\right]=\left[\begin{array}{cc}
\cos \theta_{r} & -\sin \theta_{r} \\
\sin \theta_{r} & \cos \theta_{r}
\end{array}\right]\left[\begin{array}{l}
f_{q s}^{s} \\
f_{d s}^{s}
\end{array}\right],} \\
& {\left[\begin{array}{l}
f_{q s}^{s} \\
f_{d s}^{s}
\end{array}\right]=\left[\begin{array}{cc}
\cos \theta_{r} & \sin \theta_{r} \\
-\sin \theta_{r} & \cos \theta_{r}
\end{array}\right]\left[\begin{array}{l}
f_{q s}^{r} \\
f_{d s}^{r}
\end{array}\right] .}
\end{aligned}
$$




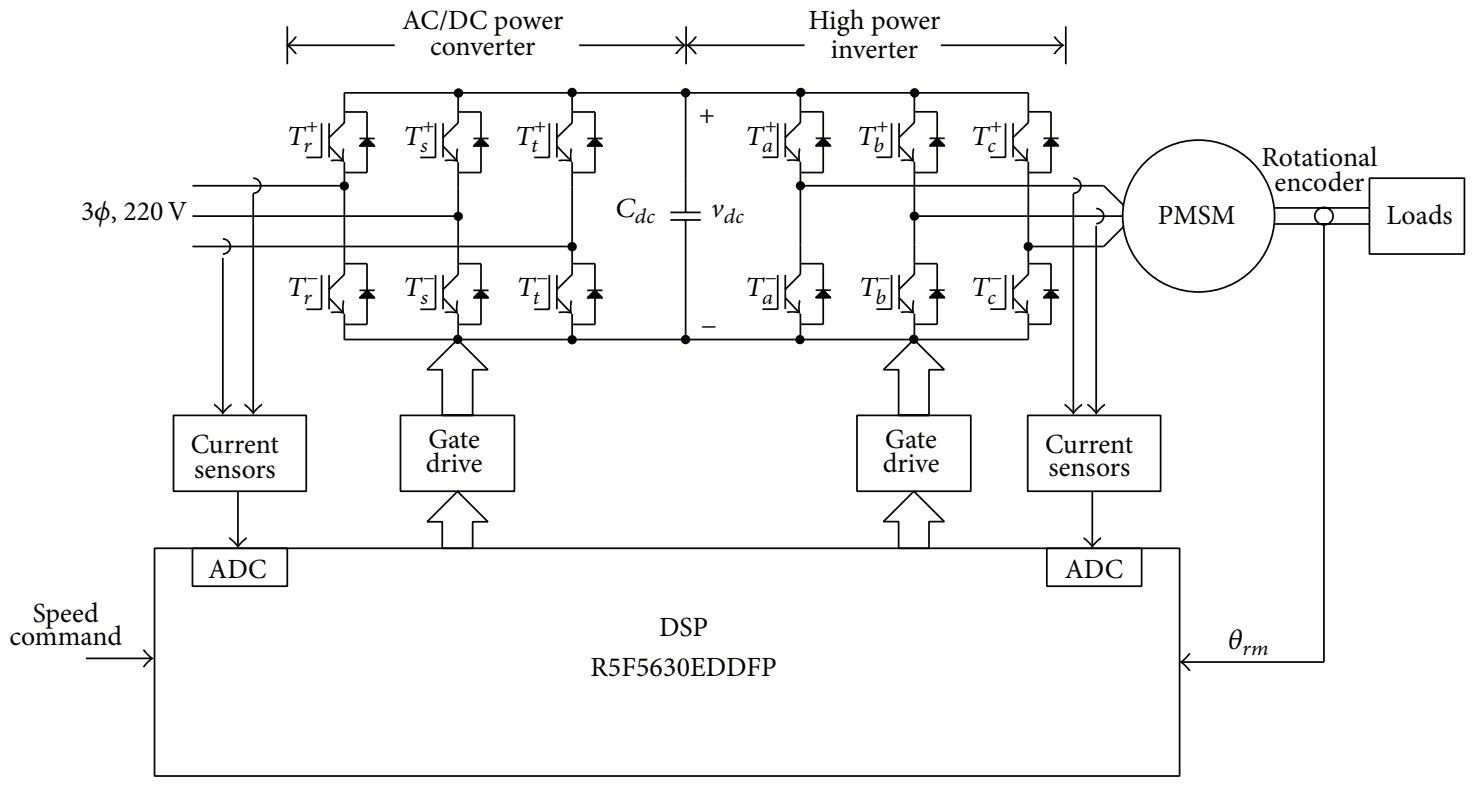

FIGURE 1: Block diagram of the proposed system.

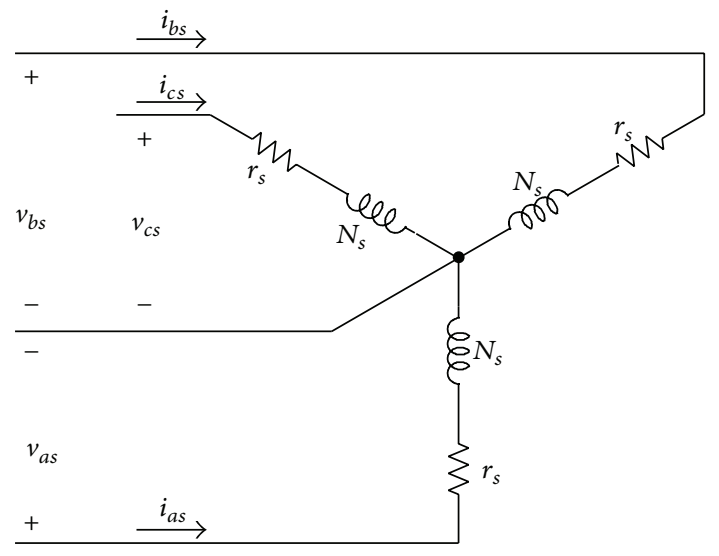

FIgURE 2: Equivalent circuit of the Y-connection PMSM.

Transforming (5) and (6) into $q$ - $d$ stationary frame with (7), one obtains

$$
\begin{aligned}
& v_{q s}^{s}=r_{s} i_{q s}^{s}+L_{s} \frac{d}{d t} i_{q s}^{s}+\omega_{r} \lambda_{m}^{\prime} \cos \theta_{r} \\
& v_{d s}^{s}=r_{s} i_{d s}^{s}+L_{s} \frac{d}{d t} i_{d s}^{s}-\omega_{r} \lambda_{m}^{\prime} \sin \theta_{r}
\end{aligned}
$$

where $v_{q s}^{s}, v_{d s}^{s}, i_{q s}^{s}$, and $i_{d s}^{s}$ are motor input voltages and currents reflecting in stationary frame, respectively. From (9), the state equation can be derived as follows:

$$
\left[\begin{array}{l}
\frac{d}{d t} i_{q s}^{s} \\
\frac{d}{d t} i_{d s}^{s}
\end{array}\right]=\left[\begin{array}{cc}
-\frac{r_{s}}{L_{s}} & 0 \\
0 & -\frac{r_{s}}{L_{s}}
\end{array}\right]\left[\begin{array}{l}
i_{q s}^{s} \\
i_{d s}^{s}
\end{array}\right]+\frac{1}{L_{s}}\left[\begin{array}{ll}
1 & 0 \\
0 & 1
\end{array}\right]\left[\begin{array}{c}
u_{q s}^{s} \\
u_{d s}^{s}
\end{array}\right],
$$

where

$$
\begin{aligned}
& u_{q s}^{s}=v_{q s}^{s}-\omega_{r} \lambda_{m}^{\prime} \cos \theta_{r}, \\
& u_{d s}^{s}=v_{d s}^{s}+\omega_{r} \lambda_{m}^{\prime} \sin \theta_{r} .
\end{aligned}
$$

It is seen from (10) that inputs and outputs are linearity in a control period if motor speed is fixed. Therefore, one can have digitalized state equation as follows [8]:

$$
\left[\begin{array}{c}
i_{q s}^{s}(k) \\
i_{d s}^{s}(k)
\end{array}\right]=\Phi_{q d}\left[\begin{array}{c}
i_{q s}^{s}(k-1) \\
i_{d s}^{s}(k-1)
\end{array}\right]+\Gamma_{q d}\left[\begin{array}{c}
u_{q s}^{s}(k-1) \\
u_{d s}^{s}(k-1)
\end{array}\right],
$$

where

$$
\Phi_{q d}=\left[\begin{array}{cc}
e^{-\left(r_{s} / L_{s}\right) T_{s}} & 0 \\
0 & e^{-\left(r_{s} / L_{s}\right) T_{s}}
\end{array}\right],
$$

$$
\Gamma_{q d}=\frac{1}{r_{s}}\left[\begin{array}{cc}
1-e^{-\left(r_{s} / L_{s}\right) T_{s}} & 0 \\
0 & 1-e^{-\left(r_{s} / L_{s}\right) T_{s}}
\end{array}\right] .
$$

$T_{s}$ denotes control cycle; $k$ and $(k-1)$ are current and last states, respectively. Equation (12) can be used in predicted current estimator.

The electromagnetic torque equation in $q$ - $d$ rotating frame can be written as

$$
T_{e}=\frac{3}{2} \frac{N_{p}}{2}\left(L_{s} i_{q s}^{r} i_{d s}^{r}+\lambda_{m}^{\prime} i_{q s}^{r}\right),
$$

where $N_{p}$ is numbers of poles. The motion equation is

$$
T_{e}=\frac{2}{N_{P}} \mathrm{~J} \frac{d}{d t} \omega_{r}+\frac{2}{N_{P}} B \omega_{r}+T_{L}
$$

where $J$ and $B$ denote the inertia and friction of motor, respectively. $\omega_{r}$ is rotor electrical speed and $T_{L}$ is the load. This means that the speed of compressor can be controlled by $i_{q s}^{r}$ and is used in this paper to implement the speed regulator of motor drive [9-11]. 


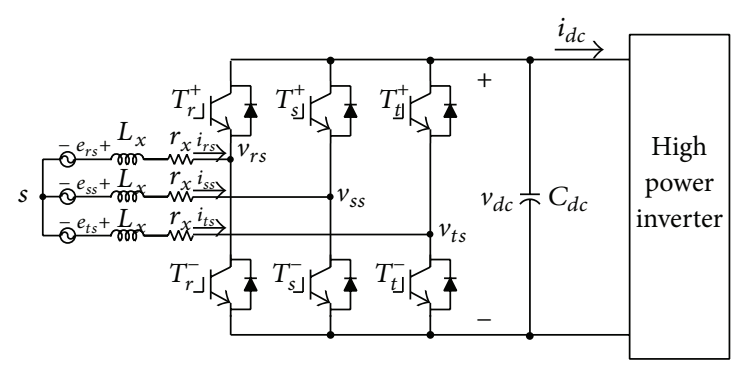

FIGURE 3: Equivalent circuit of the AC/DC power converter.

3.2. Analysis of AC/DC Power Converter. The AC/DC power converter shown in Figure 1 is implemented by three-phase switched-mode devices. The dynamic equations with inductor currents and capacitor voltage can be derived as

$$
\begin{gathered}
L_{x} \frac{d}{d t} i_{r s}=e_{r s}-r_{x} i_{r s}-v_{r s}, \\
L_{x} \frac{d}{d t} i_{s s}=e_{s s}-r_{x} i_{s s}-v_{s s}, \\
L_{x} \frac{d}{d t} i_{t s}=e_{t s}-r_{x} i_{t s}-v_{t s}, \\
C_{d c} \frac{d}{d t} v_{d c}=i_{r s} S_{r}+i_{s s} S_{s}+i_{t s} S_{t}-i_{d c},
\end{gathered}
$$

where $e_{r s}, e_{s s}$, and $e_{t s}$ and $i_{r s}, i_{s s}$, and $i_{t s}$ denote the phase voltages and line currents of utility, respectively; $v_{r s}, v_{s s}$, and $v_{t s}$ are the input voltages of converter; $S_{r}, S_{s}$, and $S_{t}$ are switching functions; $v_{d c}$ and $i_{d c}$ are the $d c$-link voltage and output current, respectively; $r_{x}$ and $L_{x}$ are resistance and inductance of utility; $C_{d c}$ is the capacitance of $d c$-link capacitor.

Assume that the switching frequency of the proposed system is high enough to yield negligible harmonic current from the system. Under this circumstance, one can derive the following inequality for proper operation of the converter:

$$
v_{d c}>2 v_{m}^{\prime}
$$

where $v_{m}^{\prime}=\sqrt{\left(v_{m}-i_{m} r_{x}\right)^{2}+\left(\omega_{e} L_{x} i_{m}\right)^{2}} ; v_{m}$ and $i_{m}$ are the peak values of voltage and current from utility, respectively, and $\omega_{e}$ is the frequency of the utility output.

The $d c$-link voltage command of the proposed system is $v_{d c}^{*}=310 \mathrm{~V}$. From (20) and the relation between $v_{m}^{\prime}$ and $\omega_{e}$, one finds that the utility frequency must lie between $50 \mathrm{~Hz}$ and $80 \mathrm{~Hz}$. This will result in a stable and fixed $d c$-link voltage for the inverter in the next stage to produce a balanced threephase $60 \mathrm{~Hz}$ voltage with a peak value of $220 \sqrt{2} \mathrm{~V}$. If $d c$-link voltage cannot satisfy the inequality constraint of (20), the system will be out of control. Similarly, from (19) one can obtain the voltage-current equation for the $d c$-link as

$$
C_{d c} \frac{d}{d t} v_{d c}=\frac{p_{x}}{v_{d c}}-i_{d c}
$$

where $p_{x} \equiv(3 / 2) v_{m} i_{m}$ is the average power from utility.
It is noted that (21) characterizes the balance of power between the utility and $d c$-link when the utility output is sinusoidal with unity power factor. Based on (21), a controller is designed to yield the current command for rectifier input.

For the sake of simplicity in analysis and control, the three-phase voltages, currents, and switching functions of (16) (18) can be transformed into synchronous frame. This gives

$$
\left[\begin{array}{c}
e_{q s} \\
e_{d s}
\end{array}\right]=\left[\begin{array}{cc}
\omega_{e} L_{x} & L_{x} p+r_{x} \\
L_{x} p+r_{x} & -\omega_{e} L_{x}
\end{array}\right]\left[\begin{array}{c}
i_{q s} \\
i_{d s}
\end{array}\right]+\left[\begin{array}{c}
v_{q s} \\
v_{d s}
\end{array}\right]
$$

where $p$ is the operator $d / d t ; e_{q s}, e_{d s}, i_{q s}$, and $i_{d s}$ are $q-d$ axis voltage and current, respectively, while $v_{q s}$ and $v_{d s}$ are the transformed $q$ - and $d$-axis voltage of the rectifier input, respectively.

Equation (22) can be rewritten as

$$
\begin{aligned}
& L_{x} \frac{d}{d t} i_{q s}=e_{q s}-v_{q s}-r_{x} i_{q s}-\omega_{e} L_{x} i_{d s}, \\
& L_{x} \frac{d}{d t} i_{d s}=e_{d s}-v_{d s}-r_{x} i_{d s}+\omega_{e} L_{x} i_{q s} .
\end{aligned}
$$

From (23), one can obtain the following voltage command for three-phase rectifier:

$$
\begin{gathered}
v_{q s}^{*}=e_{q s}-u_{q s}^{*}-\omega_{e} L_{x} i_{d s}, \\
v_{d s}^{*}=e_{d s}-u_{d s}^{*}+\omega_{e} L_{x} i_{q s},
\end{gathered}
$$

where

$$
\begin{aligned}
& u_{q s}^{*} \equiv G_{i q s} \circ\left(i_{q s}^{*}-i_{q s}\right), \\
& u_{d s}^{*} \equiv G_{i d s} \circ\left(i_{d s}^{*}-i_{d s}\right),
\end{aligned}
$$

and $G_{i q s}$ and $G_{i d s}$ are the gains of the $q$ - and $d$-axis proportional-integral current controller, respectively. The symbol "o" denotes proportional-integral operation. Applying the inverse transformation to the voltage commands obtained from (24) (25) gives the three phase output voltage commands $v_{r s}^{*}, v_{s s}^{*}$, and $v_{t s}^{*}$. After comparing with the counter values in DSP, which correspond to an $8 \mathrm{kHz}$ high frequency triangular carrier of sinusoidal PWM, the duty cycles are determined to switch the power transistors and thus forcing the actual current to follow the commanding current within one carrier cycle. This results in fast transient response in the rectifier. Further investigation of the rectifier circuit gives the following equations for the average real and reactive powers:

$$
\begin{aligned}
& p_{s}=\frac{3}{2} v_{m} i_{q s}, \\
& q_{s}=\frac{3}{2} v_{m} i_{d s} .
\end{aligned}
$$

Equation (26) indicates that $p_{s}$ depends only on $i_{q s}$, while (27) shows that setting $i_{d s}$ equal to zero implies zero reactive power and thereby results in unity input power factor and raises the efficiency of the rectifier. For the sake of keeping $d c$ voltage at output of the AC/DC power converter constant, 


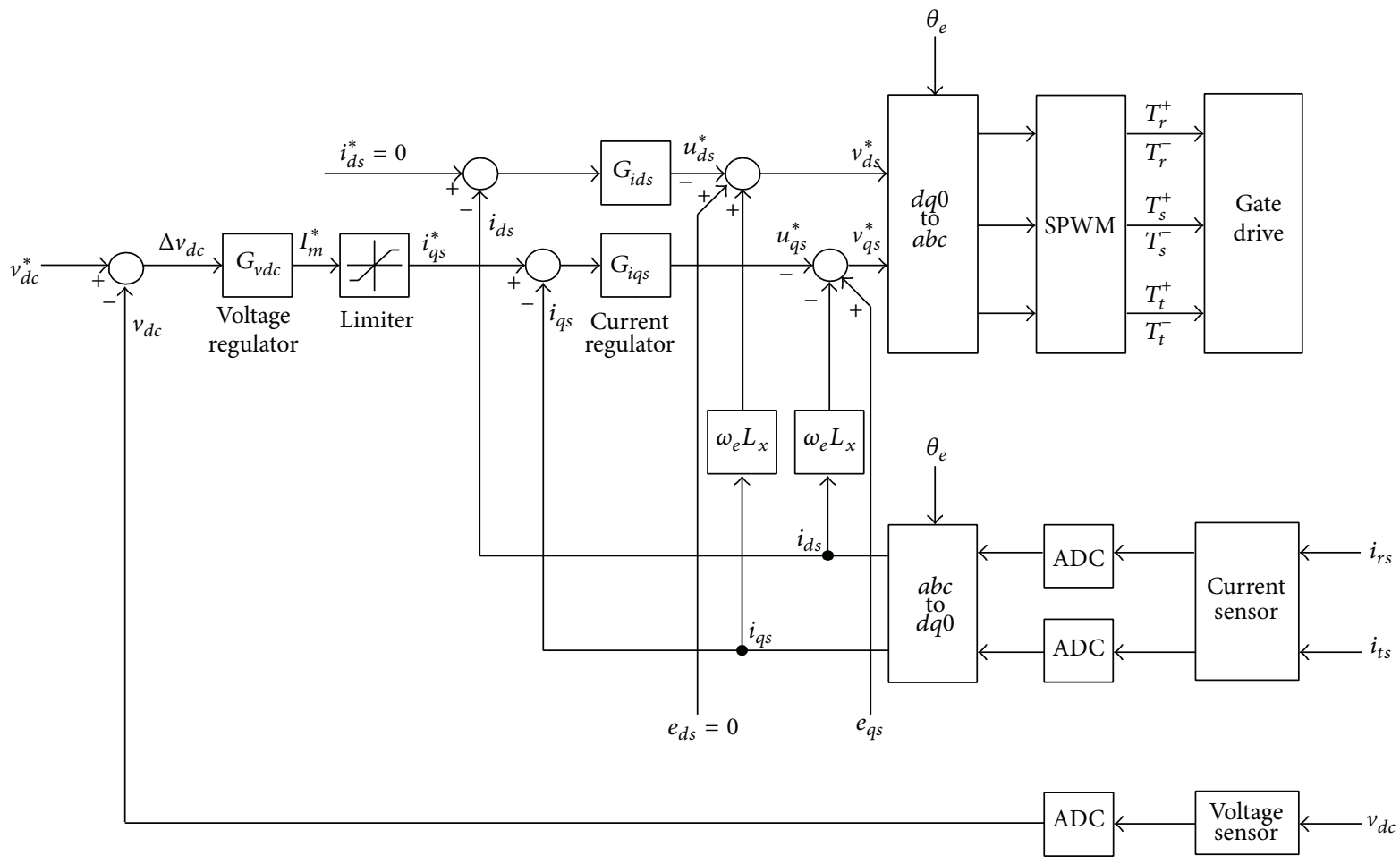

FIGURE 4: Control block diagram of the AC/DC power converter.

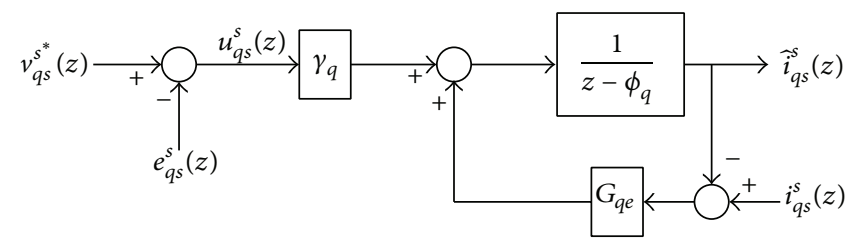

(a)

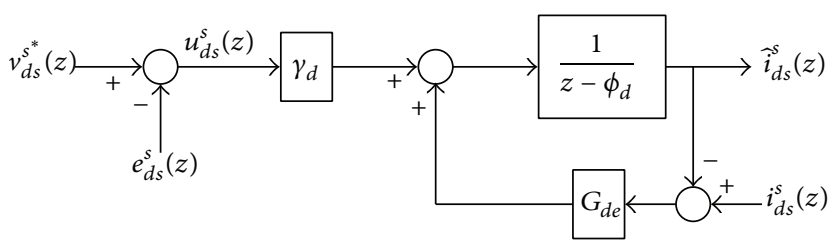

(b)

FIGURE 5: Control block diagram of the predicted current estimator: (a) $q$-axis current estimator; (b) $d$-axis current estimator.

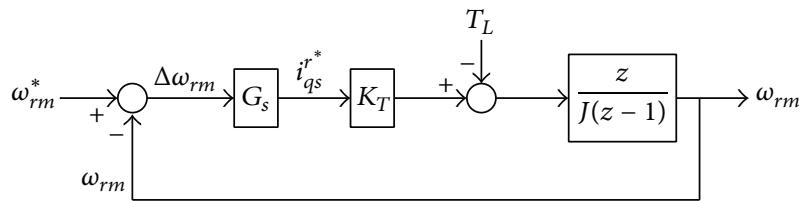

FIGURE 6: Control block diagram of the speed regulator.

$d c$-link voltage is monitored to control the input currents to ensure the balance of power between utility and $d c$-link (see Figure 3 ). This is conducted by voltage regulator which can generate the current command for predicted current controller in order to adjust $d c$-link voltage at output of the AC/DC power converter. The current command can be written as

$$
I_{m}^{*}=\left(G_{v d c} \circ \Delta v_{d c}\right)
$$

where $\Delta v_{d c} \equiv v_{d c}^{*}-v_{d c} ; G_{v d c}$ is the gain of the proportionalintegral voltage controller. For reducing the order of the closed-loop transfer function of voltage control loop, the pole-zero cancellation method was used to determine the controller parameters which yield the proportional-integral controller parameters of voltage regulator, $k_{v p}=0.62$ and $k_{v i}=83.21$. The control block diagram of the AC/DC power 


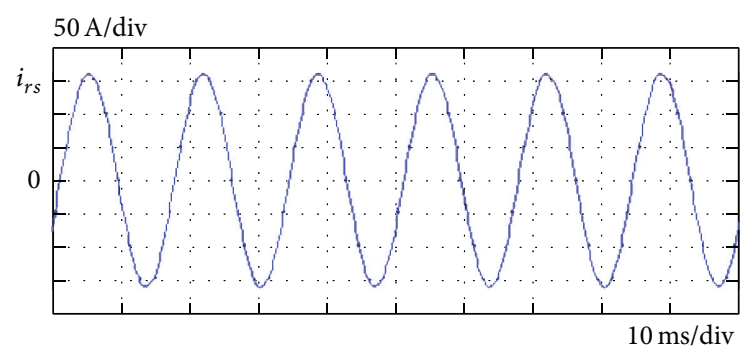

(a)

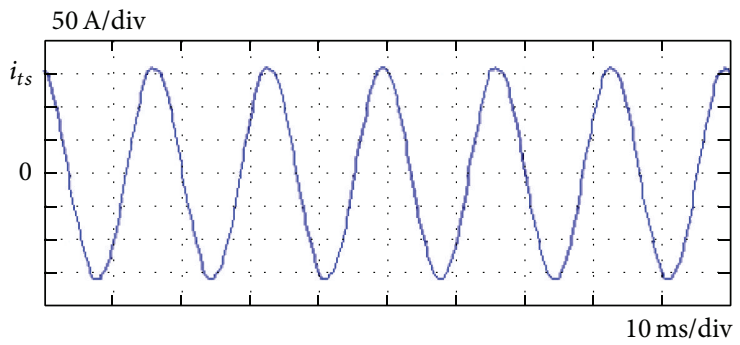

(c)

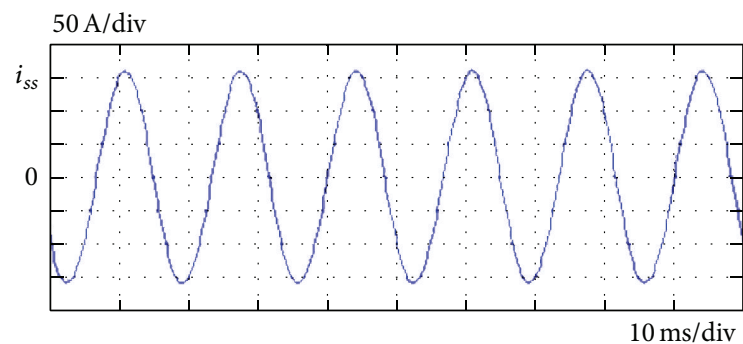

(b)

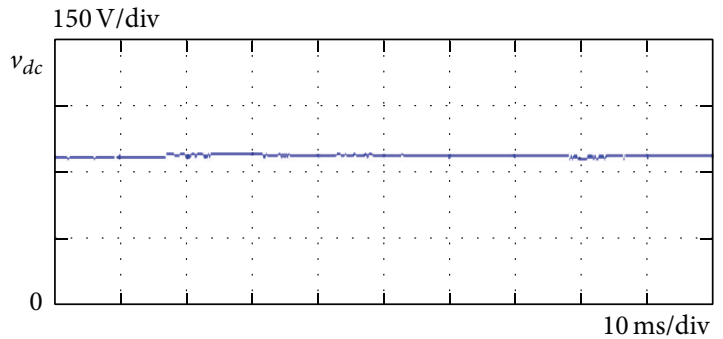

(d)

FiguRE 7: Experimental results of the proposed AD/DC power converter in steady state: (a) phase current $i_{r s}$; (b) phase current $i_{s s}$; (c) phase current $i_{t s} ;(\mathrm{d}) d c$-link voltage $v_{d c}$.

converter is shown in Figure 4, where predicted current controller under synchronous frame is used.

3.3. Analysis of Predicted Current Estimator. The proposed high power inverter is shown in Figure 1. As mentioned above, constant $d c$ voltage is supplied from the $d c$-link of the last stage. Proper control of the power transistors will transfer power from $d c$ to three-phase ac. Generally, the high frequency switching of inverters, resolution limitation of analog-to-digital converters, and sampling delays from current feedbacks introduce a large number of current harmonics. Therefore, it is difficult to design digital controller for high power drives. In order to suppress the current harmonics and improve the performance of the current regulator, the predicted current estimator is used to obtain real currents. The feedback currents from motor estimated by $q$ - and $d$ axis in stationary frame reduce time delay problems. After z-transform to (12), the control block diagram of predicted current estimator is shown in Figure 5. The predicted current estimator suppresses ripples of voltage commands to reduce current harmonics. From (12) (13), the estimated currents $\widehat{\imath}_{d s}^{s}$ and $\widehat{\imath}_{d s}^{s}$ are

$$
\begin{aligned}
& {\widehat{\tau_{q s}}}^{s}(z)=\left[v_{q s}^{s^{*}}(z)-e_{q s}^{s}(z)\right] \frac{\gamma_{q}}{z-\phi_{q}} \\
& \widehat{\imath}_{d s}^{s}(z)=\left[v_{d s}^{s^{*}}(z)-e_{d s}^{s}(z)\right] \frac{\gamma_{d}}{z-\phi_{d}},
\end{aligned}
$$

where $e_{q s}^{s}=\omega_{r} \hat{\lambda}_{m}^{\prime} \cos \theta_{r}$ and $e_{d s}^{s}=\omega_{r} \hat{\lambda}_{m}^{\prime} \sin \theta_{r}$. The current regulators of predicted current estimator can be written as

$$
\begin{aligned}
& G_{q e}=k_{p q e}+k_{i q e} \frac{z}{z-1}, \\
& G_{d e}=k_{p d e}+k_{i d e} \frac{z}{z-1},
\end{aligned}
$$

where $k_{p q e}, k_{i q e}, k_{p d e}$, and $k_{i d e}$ are gains of the proportionalintegral current regulators, respectively. If $u_{q s}^{s}=0$ and $u_{d s}^{s}=$ 0 , the transfer functions of predicted current estimator can be derived as

$$
\begin{aligned}
& \frac{i_{q s}^{s}(z)}{\widehat{\imath}_{q s}^{s}(z)}=\frac{\left(k_{p q e}+k_{i q e}\right) z-k_{i q e}}{z^{2}+\left(k_{p q e}+k_{i q e}-\phi_{q}\right) z-k_{i q e}}, \\
& \frac{i_{d s}^{s}(z)}{\widehat{\imath}_{d s}^{s}(z)}=\frac{\left(k_{p d e}+k_{i d e}\right) z-k_{i d e}}{z^{2}+\left(k_{p d e}+k_{i d e}-\phi_{d}\right) z-k_{i d e}} .
\end{aligned}
$$

The predicted current estimator improves the accuracy of current feedback and reduces current harmonics to motor. It not only can improve the current sampling delay, but also has the characteristics of low-pass filters to enhance system stability.

3.4. Analysis of Speed Regulator. It is seen from (14) that the electromagnetic torque of motor is proportional to $q$ axis current. This means that the output speed of motor can be controlled by $q$-axis current $i_{q s}^{r}$ and is used in this paper to implement the speed regulator. Therefore, the $q$ axis current command $i_{q s}^{r^{*}}$ can be calculated by speed error to speed regulator $G_{s}$. It is important to note that the friction of this motor is ignored due to high inertia in the high power PMSM. This yields

$$
G_{s}=k_{p s}+k_{i s} \frac{z}{z-1},
$$




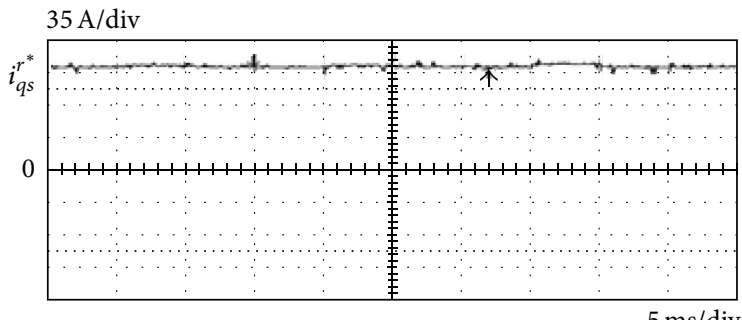

(a)

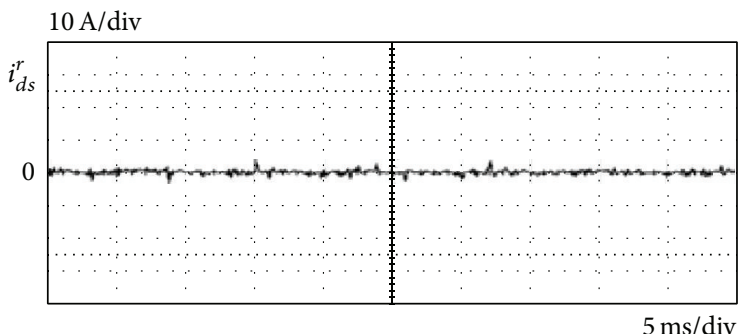

(c)

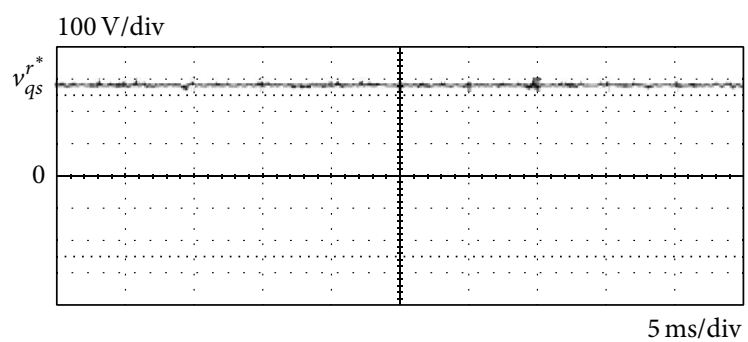

(e)

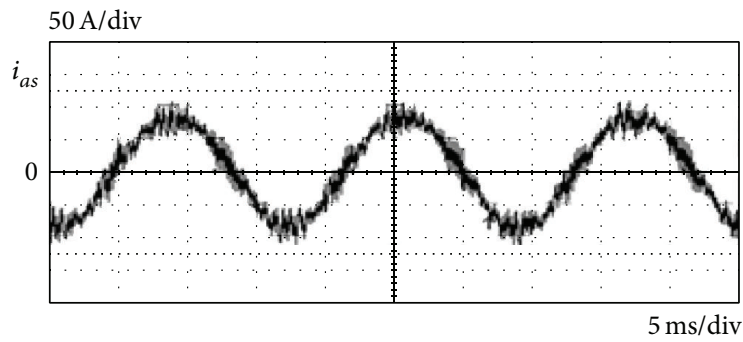

(g)

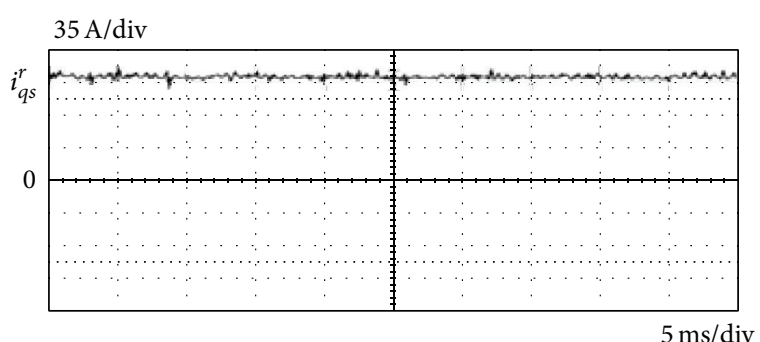

(b)

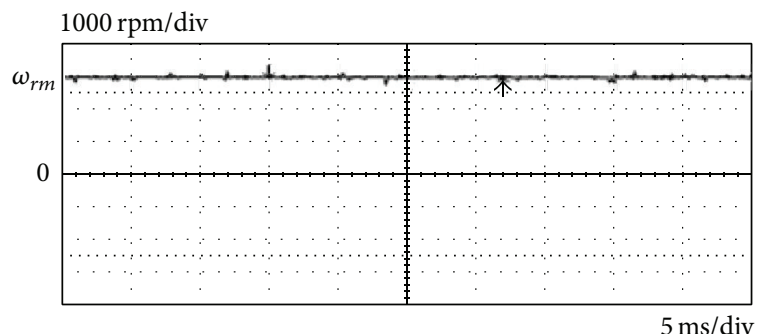

(d)

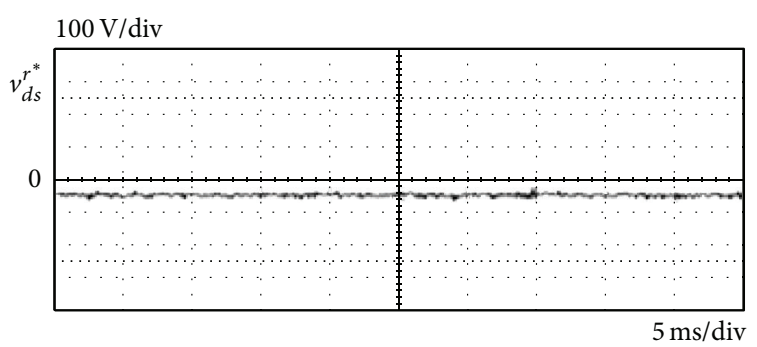

(f)

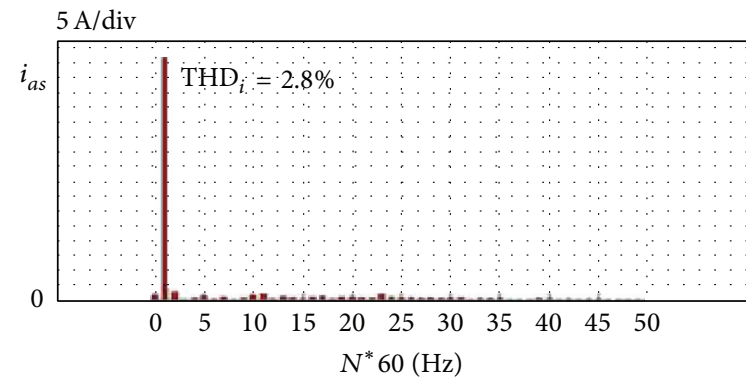

(h)

FIGURE 8: Experimental results of the proposed system in steady state: (a) $q$-axis current command $i_{q s}^{r^{*}}$; (b) $q$-axis current $i_{q s}^{r}$; (c) $d$-axis current $i_{d s}^{r} ;$ (d) motor speed $\omega_{r m} ;$ (e) $q$-axis voltage command $v_{q s}^{r^{*}}$; (f) $d$-axis voltage command $v_{d s}^{r^{*}}$; (g) output current $i_{a s}$; (h) total harmonic distortion of output current $i_{a s}$.

where $k_{p s}$ and $k_{i s}$ are gains of the proportional-integral current regulators, respectively. The transfer functions of speed regulator can be derived as

$$
\begin{aligned}
& \left.\frac{\omega_{r m}}{\omega_{r m}^{*}}\right|_{T_{L}=0}=\frac{K_{T}\left(k_{p s}+k_{i s}\right) z^{2}-k_{p} K_{T} z}{\left(k_{p s} K_{T}+k_{i s} K_{T}+J\right) z^{2}-\left(k_{p s} K_{T}+2 J\right) z+J}, \\
& \left.\frac{\omega_{r m}}{T_{L}}\right|_{\omega_{r m}^{*}=0}=\frac{-z^{2}+z}{\left(k_{p s} K_{T}+k_{i s} K_{T}+J\right) z^{2}-\left(k_{p s} K_{T}+2 J\right) z+J} .
\end{aligned}
$$

The control block diagram of speed regulator is shown in Figure 6. Experimental evaluation of the proposed system will be given in the following section.

3.5. Parameters Selection. For fixed switching frequency, the switching and conducting losses are almost proportional to the amplitude of the correlative currents. Therefore, the total loss of switching devices can be computed from the circuit parameters and the $q$ - and $d$-axis currents of the AC/DC power converter and the inverter. The machine and electric 


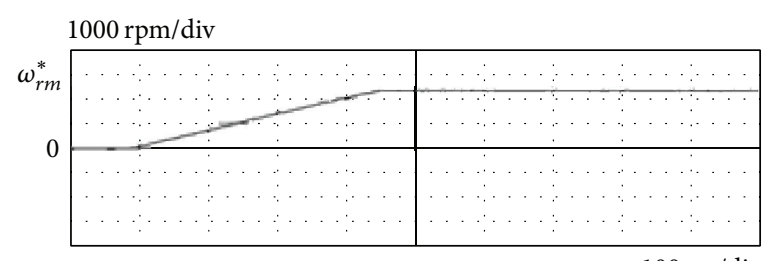

(a)

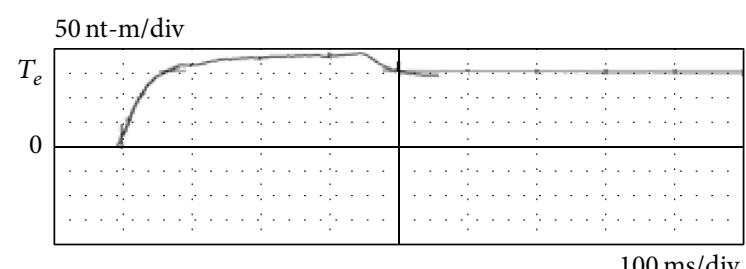

(c)

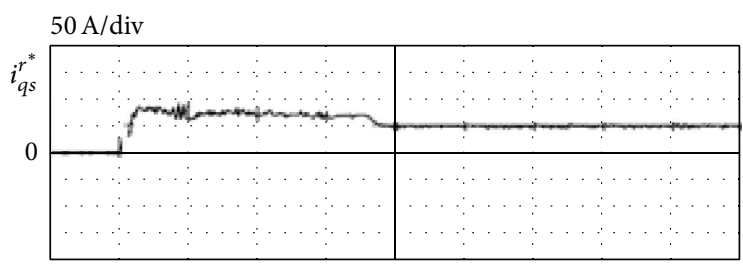

$100 \mathrm{~ms} / \mathrm{div}$

(e)

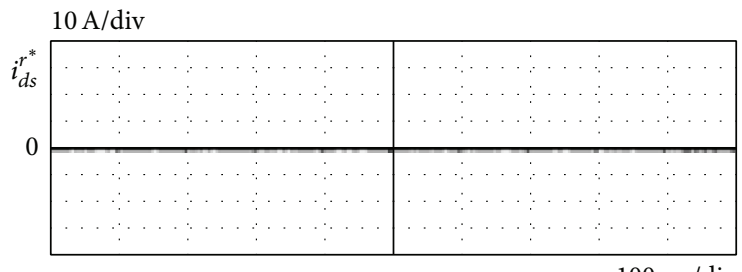

(g)

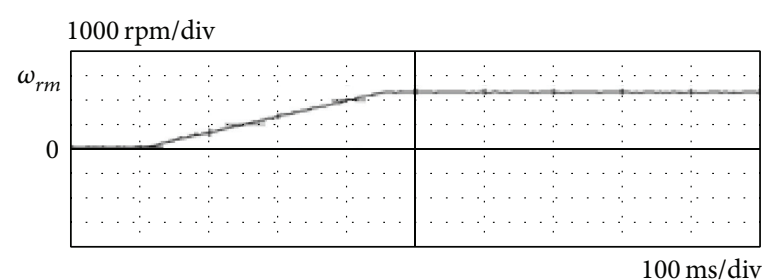

(b)

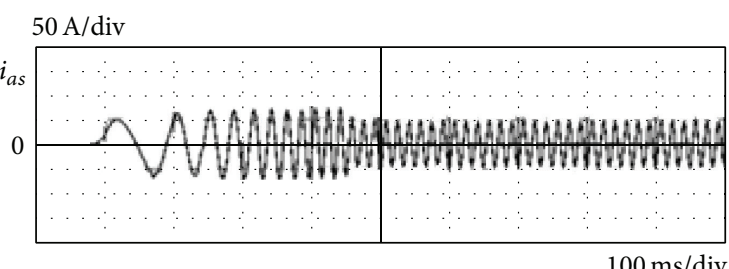

(d)

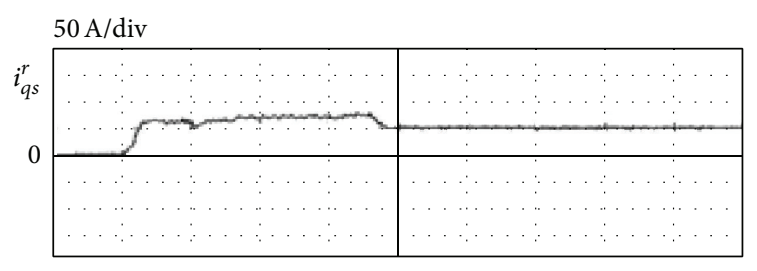

$100 \mathrm{~ms} / \mathrm{div}$

(f)

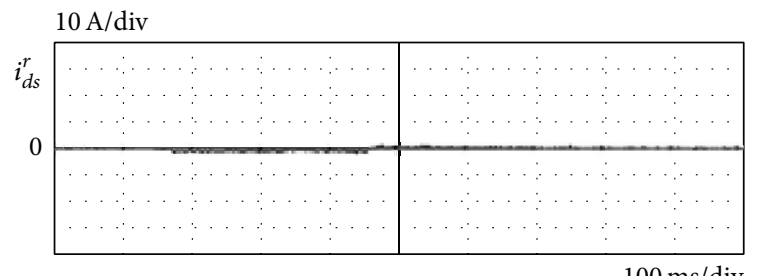

(h)

FIGURE 9: Experimental results of the proposed system under 0 2200 rpm speed variations: (a) motor speed command $\omega_{r m}^{*}$; (b) motor speed $\omega_{r m} ;$ (c) electromagnetic torque $T_{e}$; (d) phase current $i_{a s}$; (e) $q$-axis current command $i_{q s}^{r^{*}}$; (f) $q$-axis current $i_{q s}^{r}$; (g) $d$-axis current command $i_{d s}^{r^{*}} ;(\mathrm{h}) d$-axis current $i_{d s}^{r}$.

parameters of PMSM are given in Table 1. For reducing the order of the closed-loop transfer function of voltage and current loops in AC/DC power converter and speed loop in high power inverter, the pole-zero cancellation method is used to determine the control parameters of voltage regulator, $k_{v p}=0.502, k_{v i}=81.36$; current regulator, $k_{i d q p}=$ $3.02, k_{i d q i}=43.278$; and speed regulator, $k_{s p}=55.321$, $k_{s i}=13.52$, respectively.

\section{Experimental Results}

An experimental prototype of a $75 \mathrm{~kW}$ motor drive for PMSM was built with machine and electric parameters shown in Table 1. The DSP R5F5630EDDFP mentioned above was used to implement the control scheme. The power controller was formed by insulated-gate bipolar transistors (IGBT), which operates at $8 \mathrm{kHz}$. Figure 7 shows measured waveforms
TABLE 1: Machine and electric parameters of PMSM.

\begin{tabular}{lc}
\hline Machine parameters & Electric parameters \\
\hline Rated speed: $3600 \mathrm{rpm}$ & $\lambda_{m}^{\prime}=0.055 \mathrm{~V}-\mathrm{s} / \mathrm{rad}$ \\
Rated torque: $200 \mathrm{nt}-\mathrm{m}$ & $r_{s}=6.2 \mathrm{~m} \Omega$ \\
Rated power: $75 \mathrm{~kW}$ & $L_{s}=0.0034 \mathrm{mH}$ \\
Line voltage: $220 \mathrm{Vrms}$ & \\
Line current: $200 \mathrm{Arms}$ & \\
Pole number: 12 & \\
\hline
\end{tabular}

of the input currents and $d c$-link voltage of the AC/DC power converter under load of $50 \mathrm{~kW}$ in the steady state. It illustrates that the input currents were almost sinusoidal with low harmonic distortion, whereas the $d c$-link voltage $v_{d c}$ remained constant. Figure 8 shows experimental results of 


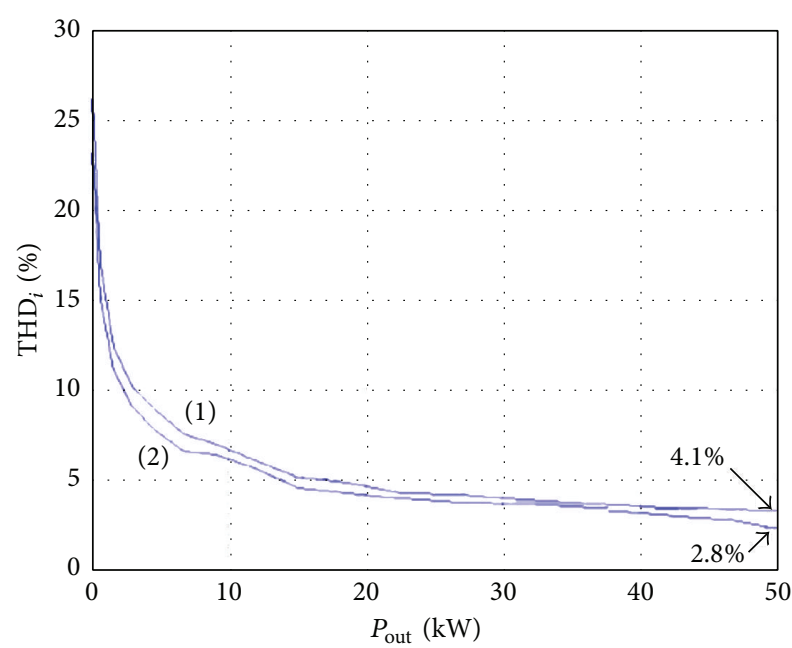

(1) Without predicted current estimator

(2) With predicted current estimator

Figure 10: Total harmonic distortion of currents versus output power.

the proposed system under the rotor speed $3000 \mathrm{rpm}$ with $50 \mathrm{~kW}$ power output. It can be seen that the current ripples of $q$ - and $d$-axis are small when $d$-axis current comment sets to zero. Figure 9 illustrates motor speed command $\omega_{r m}^{*}$, motor speed $\omega_{r m}$, electromagnetic torque $T_{e}$, phase current $i_{a s}, q$-axis current command $i_{q s}^{r^{*}}, q$-axis current $i_{q s}^{r}, d$-axis current command $i_{d s}^{r^{*}}$, and $d$-axis current $i_{d s}^{r}$ of the proposed system under the motor speed of $0 \sim 2200 \mathrm{rpm}$. It shows that the speed response of PMSM was fast and the torque ripple was small due to predicted current estimator. It is also seen from Figure 10 that the measured total harmonic distortion of currents reduced with predicted current estimator, and the total harmonic distortion of currents gradually declined when the output power increases. Besides, the total harmonic distortion of currents decreases to $2.8 \%$ in $50 \mathrm{~kW}$ power output. It is obvious to say that the electromagnetic torque ripple is very small under this circumstance. Therefore, the proposed system satisfies the design requirement.

\section{Conclusions}

This paper is focused on the design of digital controller for high power PMSM drives. The parameters of digital controller are derived by proposed predicted current estimator to reduce total harmonic distortion of motor currents. With theoretical derivation of design parameters, the digital controller maintains drive operating stably by setting $d$-axis current to zero with motor speed range from 0 to $3000 \mathrm{rpm}$. Comparing without predicted current estimator in $50 \mathrm{~kW}$ power output, experimental results show measured total harmonic distortion of currents are $1.3 \%$ decreased. In this paper, a DSP performs as the core controller to reduce the complexity of hardware circuit. The entire digital control algorithms are conducted by software to make high stability of drive system. In short, it could be considerable potentially to implement the high power servo drives.

\section{Conflict of Interests}

The authors declare that there is no conflict of interests regarding the publication of this paper.

\section{Acknowledgments}

The authors wish to express their sincere appreciation to UCHI OPTOELECTRONIC (M) SDN. BHD. for supporting this research. The authors would like to thank the anonymous reviewers for their valuable comments and suggestions to improve the quality of the paper.

\section{References}

[1] A. V. Sant, K. R. Rajagopal, and N. K. Sheth, "Permanent magnet synchronous motor drive using hybrid PI speed controller with inherent and noninherent switching functions," IEEE Transactions on Magnetics, vol. 47, no. 10, pp. 4088-4091, 2011.

[2] Y. Zhang and J. Zhu, "A novel duty cycle control strategy to reduce both torque and flux ripples for DTC of permanent magnet synchronous motor drives with switching frequency reduction," IEEE Transactions on Power Electronics, vol. 26, no. 10, pp. 3055-3067, 2011.

[3] Y. Zhang, J. Zhu, W. Xu, and Y. Guo, "A simple method to reduce torque ripple in direct torque-controlled permanent-magnet synchronous motor by using vectors with variable amplitude and angle," IEEE Transactions on Industrial Electronics, vol. 58, no. 7, pp. 2848-2859, 2011.

[4] H. Zhu, X. Xiao, and Y. Li, "Torque ripple reduction of the torque predictive control scheme for permanent-magnet synchronous motors," IEEE Transactions on Industrial Electronics, vol. 59, no. 2, pp. 871-877, 2012.

[5] F. Zhao, T. A. Lipo, and B.-I. Kwon, "A novel two-phase permanent magnet synchronous motor modeling for torque ripple minimization," IEEE Transactions on Magnetics, vol. 49, no. 5, pp. 2355-2358, 2013.

[6] Y. Zhang and J. Zhu, "Direct torque control of permanent magnet synchronous motor with reduced torque ripple and commutation frequency," IEEE Transactions on Power Electronics, vol. 26, no. 1, pp. 235-248, 2011.

[7] T.-C. Jeong, W.-H. Kim, M.-J. Kim et al., "Current harmonics loss analysis of $150-\mathrm{kW}$ traction interior permanent magnet synchronous motor through co-analysis of $\mathrm{d}-\mathrm{q}$ axis current control and finite element method," IEEE Transactions on Magnetics, vol. 49, no. 5, pp. 2343-2346, 2013.

[8] D. Q. Wei, B. Zhang, D. Y. Qiu, and X. S. Luo, "Effects of current time-delayed feedback on the dynamics of a permanent-magnet synchronous motor," IEEE Transactions on Circuits and Systems II: Express Briefs, vol. 57, no. 6, pp. 456-460, 2010.

[9] R. Ortega, L. Praly, A. Astolfi, J. Lee, and K. Nam, "Estimation of rotor position and speed of permanent magnet synchronous motors with guaranteed stability," IEEE Transactions on Control Systems Technology, vol. 19, no. 3, pp. 601-614, 2011.

[10] Y. Ge, C. Wang, X. Zhou, and H. Wang, "Research on rotor position sensing of a permanent magnet synchronous motor 
based on high-frequency voltage injection and Kalman filter," in Proceedings of the International Conference on Electrical and Control Engineering (ICECE '10), pp. 1750-1754, June 2010.

[11] Y. Lei, X. Fei, S. Jian-qing, C. Ming-liang, S. Qiao-ming, and Q.-F. Li, "Sensorless control of high-power interior permanentmagnet synchronous motor drives at very low speed," IET Electric Power Applications, vol. 7, no. 3, pp. 199-206, 2013. 


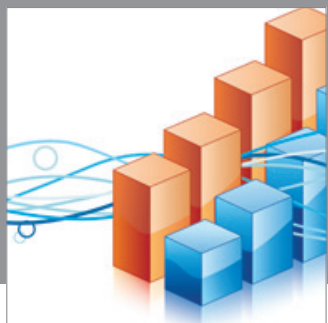

Advances in

Operations Research

mansans

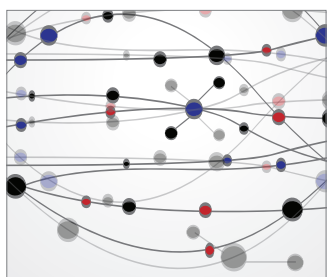

The Scientific World Journal
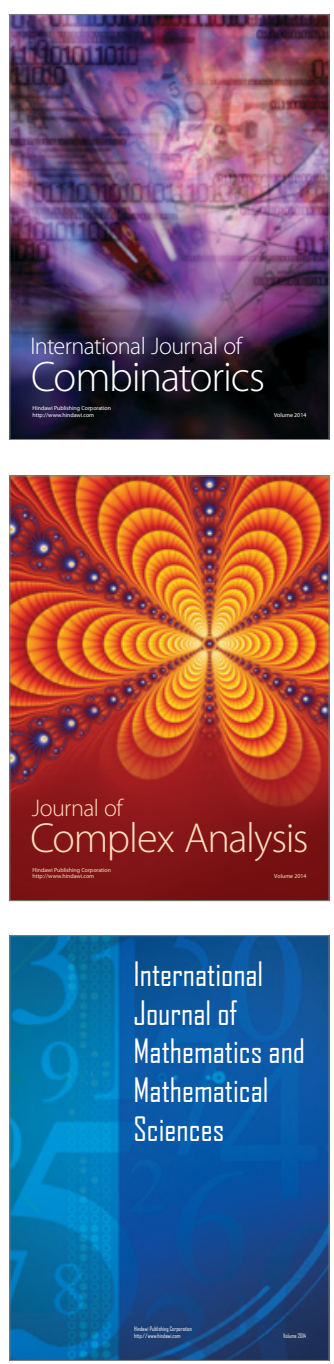
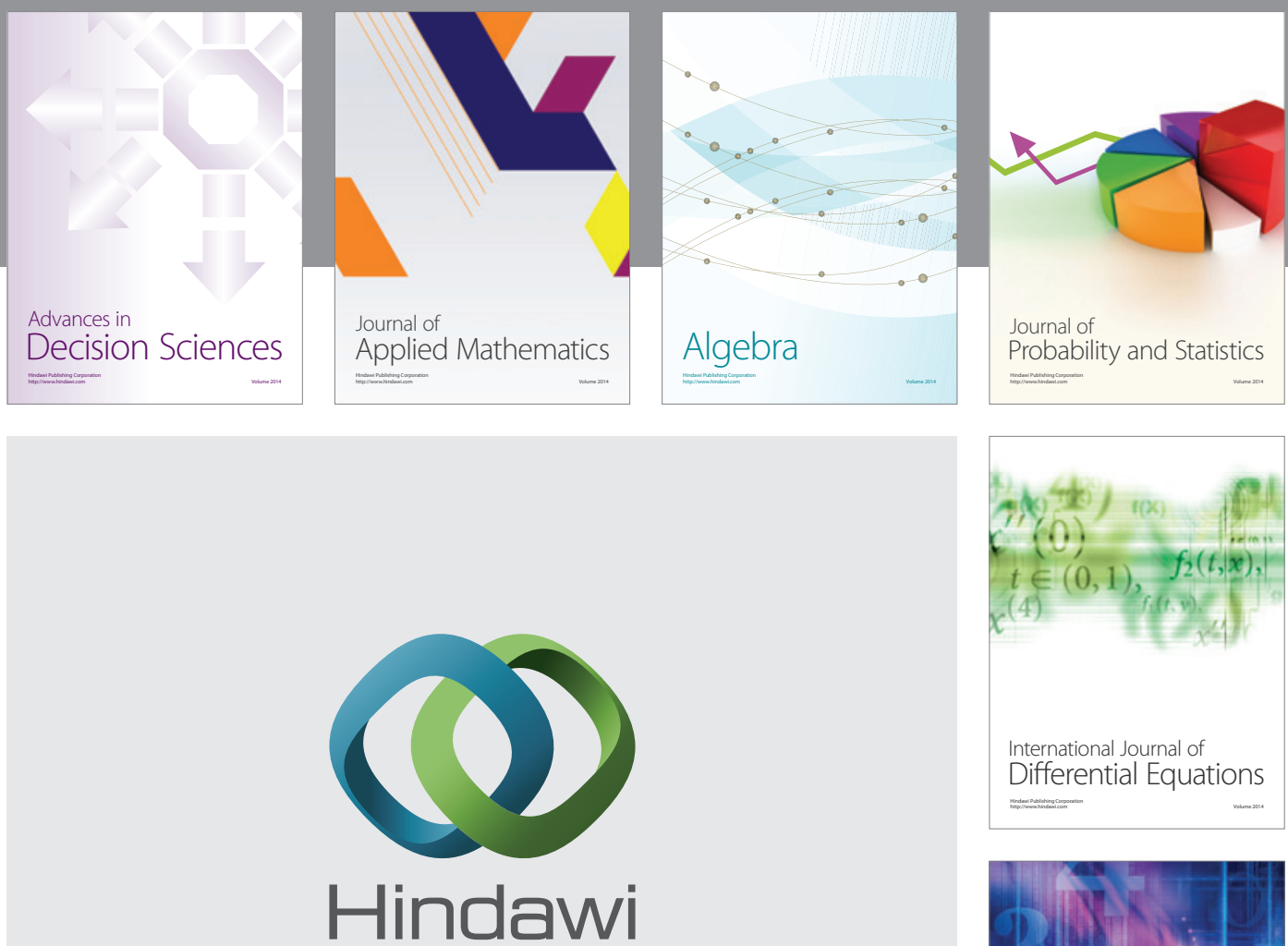

Submit your manuscripts at http://www.hindawi.com
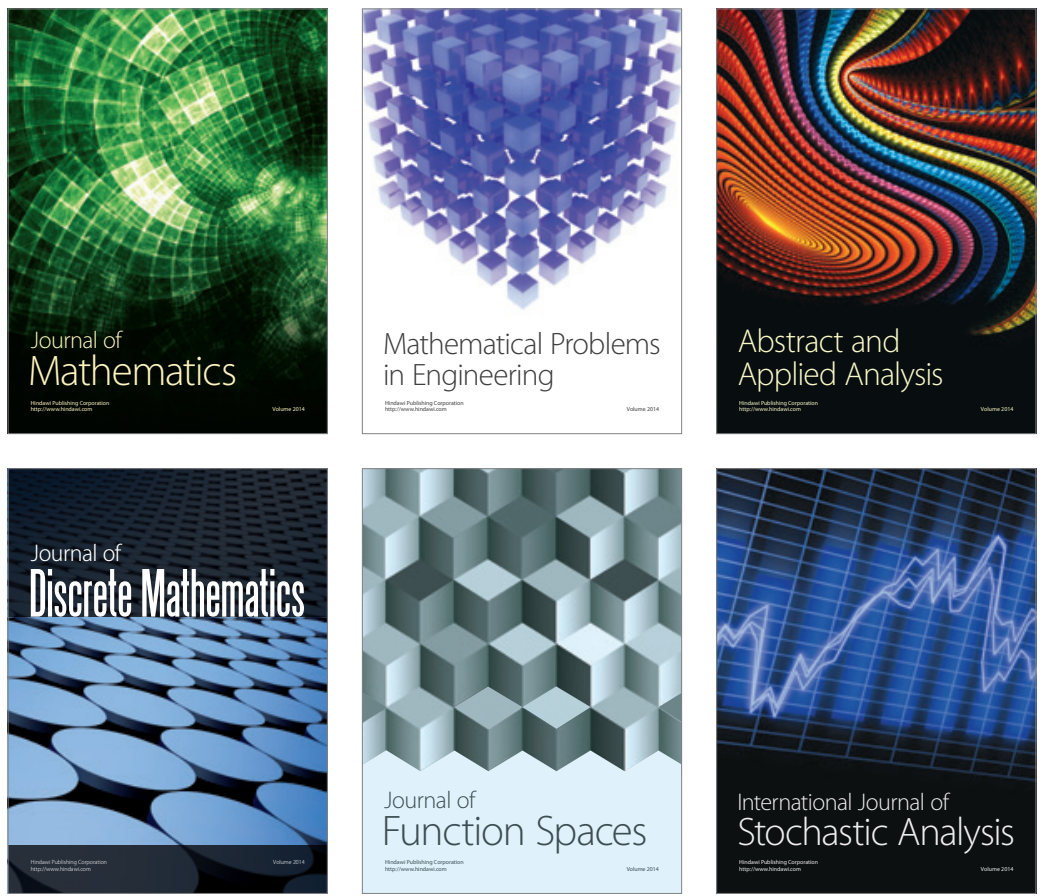

Journal of

Function Spaces

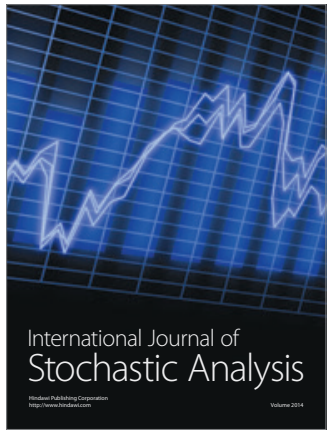

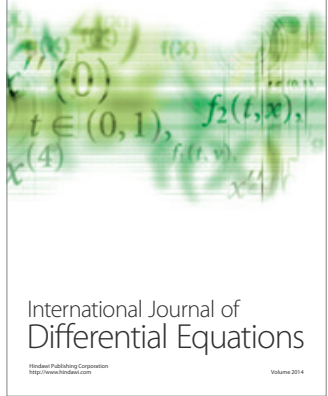
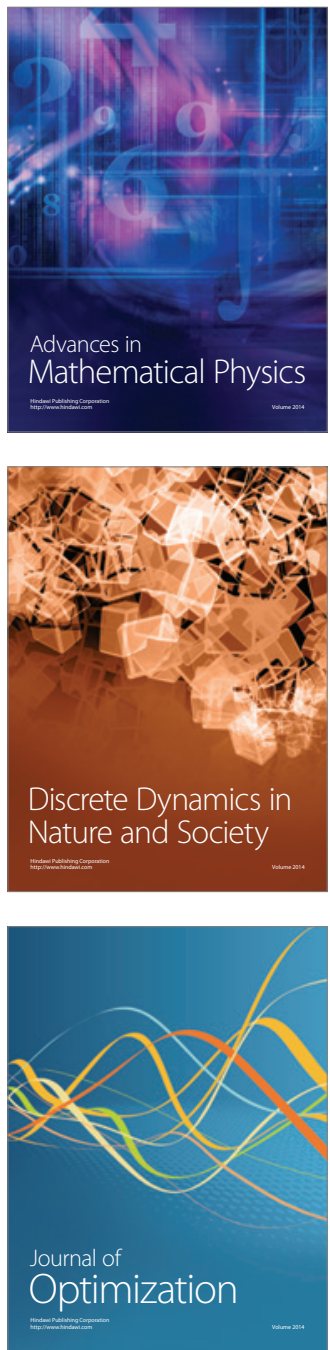